\title{
Who consumed 5 or more portions of fruit and vegetables per day in 1986-1987 and in 2000-2001?
}

\author{
Stephen Rogers ${ }^{1}$ and Jane A Pryer ${ }^{2, *}$ \\ ${ }^{1}$ NHS Northamptonshire, Northampton, UK: ${ }^{2}$ Department of Epidemiology and Public Health, Royal Free and \\ University College Medical School, University College London, Gower Street Campus, 1-19 Torrington Place, \\ London WC1E 6BT, UK
}

Submitted 14 February 2011: Accepted 9 November 2011: First published online 21 December 2011

\begin{abstract}
Objective: The aim of the study was to describe who ate 5 or more portions of fruit and vegetables per day ('compliers') in 1986-1987 and in 2000-2001.

Design: We used data from the Dietary and Nutritional Surveys of British Adults. Each is a nationally representative dietary survey using $7 \mathrm{~d}$ weighed food records for men and women, aged 16-64 years, living in private households in Great Britain in 1986-1987 and in 2000-2001.

Setting: Great Britain.

Subjects: Data were analysed for 2197 adults in 1986-1987 and 1724 adults in 2000-2001.

Results: In 1986-1987 12.7\% were classified as 'compliers' compared with 16.5\% in 2000-2001. Manual social classes, younger participants and people on benefits or outside paid employment were less likely to be 'compliers'. Being divorced, widowed or separated was negatively related to being a 'complier', as was being in a household with dependant children or a lone parent with dependant children. Between 1986-1987 and 2000-2001 improvements were seen across social class groups and differences between men and women and between regions were reduced.

Conclusions: Only $12 \cdot 7 \%$ participants in the Dietary and Nutritional Surveys of British Adults were classified as 'compliers' in 1986-1987 compared with 16.5\% in 2000-2001. There have been some important changes in the distribution of 'compliers', but the low levels overall support the need for a reinvigorated policy drive to improve compliance with fruit and vegetable goals.
\end{abstract}

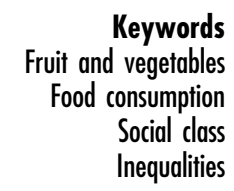

The Global Burden of Disease Study for 2000 estimated that up to $2 \cdot 7$ million deaths worldwide and $1 \cdot 8 \%$ of the global disease burden may be attributed to inadequate levels of fruit and vegetable consumption (figures for disease burden in New Zealand, Australia and the European Union were respectively $2 \cdot 4 \%, 2 \cdot 8 \%$ and $3 \cdot 5 \%$ ), and the authors suggested scope to reduce IHD by $31 \%$ and ischaemic stroke by $19 \%$ through dietary change. For stomach, oesophageal, lung and colorectal cancer the estimated reductions were 19\%, 20\%, 12\% and 2\%, respectively ${ }^{(1-4)}$.

In the UK, the Scottish Diet Report in 1993 provided the first quantified fruit and vegetable targets to double consumption to increase the average in the population to $400 \mathrm{~g} / \mathrm{d}^{(5)}$. A year later, the report by the Committee on Medical Aspects of Food Policy ${ }^{(6)}$ recommended that fruit and vegetable intake nationally be increased by $50 \%$ (from an average of 3 up to 6 portions per day ${ }^{(5)}$ ). The Scottish Diet Action Plan ${ }^{(7)}$ and the recommendations of the Nutrition Task Force ${ }^{(8)}$ represent the key policy drivers for change during the decade preceding the gathering effort through the WHO European Office and the First Action Plan for Food and Nutrition Policy, WHO European Region ${ }^{(9)}$.

Previous analyses of the 1986-1987 cohort participating in the Dietary and Nutritional Surveys of British Adults drew attention to the wide variation in fruit and vegetable consumption among British adults ${ }^{(10,11)}$. Being younger, being single, divorced or separated, belonging to a manual social class, being in receipt of benefits and living in the North of England and Scotland were all associated with a lower intake of fruit, and focused attention on the need to address consumption, access and attitudes in groups that included low consumers of fruit and vegetables.

The aim of the present paper is to examine the impact of a key phase of nutrition policy on compliance with fruit and vegetable goals in the population overall and more particularly across subgroups where differentials have previously been identified. We base our research on analyses of data from the Dietary and Nutritional Surveys 
of British Adults that allows us to compare and contrast who complied with the fruit and vegetables goals in the UK in 1986-1987 and then in 2000-2001.

\section{Methods}

The definition of fruit and vegetables used in our analysis is that established by the UK government Nutrition Task Force as discussed by Williams ${ }^{(12)}$. Fruit and vegetables include frozen and canned fruit and vegetables, those used as the main ingredients in recipes, baked beans, dried fruit and fruit juice. The definition excludes potatoes and nuts. Portions are taken to approximate $80 \mathrm{~g}^{(13)}$. In 2002, an Expert Consultation for the $\mathrm{WHO}$ and the FAO assessed the strength of the evidence for the relationship between fruit and vegetable intake and health and recommended a daily intake of fruit and vegetables of at least 400 to $500 \mathrm{~g}^{(14)}$. The World Cancer Research Fund subsequently recommended a population average consumption of non-starchy vegetables and fruit of at least $600 \mathrm{~g} / \mathrm{d}$ and a personal consumption of at least $400 \mathrm{~g} / \mathrm{d}^{(15)}$. We interpret these recommendations as consistent and equivalent to 5 servings per day (excluding potatoes and tubers).

The databases used were the Dietary and Nutritional Survey of British Adults (DNSBA) 1986-1987 and 2000-2001. The conduct and results of the surveys have been described in detail elsewhere ${ }^{(16,17)}$. Briefly, for both surveys fieldwork was carried out in four waves (July-September, October-December, January-March and April-June). The sample was recruited using a multistage random probability design, with recruitment balanced across the four waves to account for seasonality. For 1986-1987 the electoral roll was used as the sampling frame. The frame was stratified by region, and, within each major stratum, electoral wards were ranked by the proportion of heads of households in different socio-economic groups using census data. A total of 120 wards were selected as first stage units, with probability proportional to the total electorate in each ward. In each ward, thirty-three addresses were selected and one individual from each household was selected using the technique developed by Kish ${ }^{(18)}$. In total, 1087 men and 1110 women aged 16-64 years completed the full dietary survey, a response rate of $70 \%{ }^{(16)}$.

For 2000-2001 postal sectors were selected as the first stage units. The sampling frame included all postal sectors within mainland Great Britain. The frame was stratified using 1991 census data. A total of 152 postal sectors were selected as first stage units, with probability proportion to the number of postal delivery points, and thirty-eight sectors were allocated to each of the four waves. For each postal sector forty addresses were randomly selected. Eligibility was defined as being aged between 19 and 64 years and not pregnant or breast-feeding. In total 1724 adults ( 766 men and 958 females) completed the $7 \mathrm{~d}$ weighed intake, a $47 \%$ response rate ${ }^{(17)}$.
The surveys used closely comparable approaches, designed so that an interview could provide information about sociodemographic circumstances of the respondent and their families (including the Registrar General's Social Class ${ }^{(19)}$ from the occupation of the head of household); their medication and eating and drinking habits; a weighed dietary record of all food and drink consumed over seven consecutive days; physical measurements of the respondent (weight and height for 1986-1987 and also waist and hip measurements for the 2000-2001 survey); and blood pressure measurements, a $24 \mathrm{~h}$ urine collection and a blood sample.

For the dietary record, each respondent was issued with a set of accurately calibrated Soehnle digital food scales and was asked to keep a weighed record of all food and drink consumed over the $7 \mathrm{~d}$. The respondent was also provided with a 'eating and drinking away from home' diary, for use when foods could not be weighed, and was asked to record a description of the portion size and type of food eaten. All home food recipes were collected, and if the respondent ate in the workplace then the interviewer was required to visit the canteen and speak to the catering manager about portion sizes, cooking information and fats and recipes used.

A food code list of 3500 items and a full description of each item was prepared by nutritionists at the Food Standards Agency. As interviews continued more codes were added. The diary was checked by computer for completeness and consistency. Information from the diet records were linked to the nutrient databank, so that nutrients could be calculated from the diet records. The data sets for 1986-1987 and 2000-2001 were checked systematically to ensure consistency of labels and necessary adjustments were made to units of measurement to allow comparisons.

\section{Statistical analysis}

The group of interest was those who complied with fruit and vegetable goals.

Study participants were classified as 'compliers' if they consumed at least 5 portions ( $80 \mathrm{~g}$ per portion) of fruit and vegetables per day. The definition of fruit and vegetables includes frozen and canned fruit and vegetables, those used as the main ingredients in recipes, baked beans, dried fruit and only $80 \mathrm{~g}$ of fruit juice. The definition excludes potatoes and nuts. With portions taken as $80 \mathrm{~g}, 5$ or more portions per day would be at least $400 \mathrm{~g} / \mathrm{d}$. 'Non-compliers' were those who ate less than 5 portions per day.

Descriptive analyses were conducted to describe the two samples in terms of demographic and socio-economic variables, and also in terms of demographic and socioeconomic variables by 'compliers' and 'non-compliers', for 1986-1987 and for 2000-2001, using the svy $t$ tests and svy $\chi^{2}$ tests equivalents for survey data in the STATA statistical software package version 10 (StataCorp LP, College Station, TX, USA), which adjusts for the clustering sample effect 
associated with selection of electoral wards in 1986-1987 and postcode sectors in 2000-2001.

Logistic regression analyses were conducted with adjustment for clustering (svy logistic regression) ${ }^{(20)}$. The variables listed below were those which we hypothesized would be related to 'compliers' of fruit and vegetable goals, so that the regression model was hypothesis driven. The variables for the model were: age group, social class, employment status, region, marital status and household type, gender, whether receiving benefits, whether receiving food supplements, smoking and year of the survey.

\section{Results}

\section{Sociodemographic profile of the two samples - 1986-1987 and 2000-2001}

Table 1 describes demographic and socio-economic characteristics of the samples for 1986-1987 and 2000-2001.

The mean age of the sample was significantly greater in 2000-2001 compared with 1986-1987 $(P<0 \cdot 0001)$ and the mean BMI was also significantly greater in 2000-2001 compared with 1986-1987 ( $P<0 \cdot 0001)$, for both men and women. There was no difference in the sample selected by region between 1986-1987 and 2000-2001. There were significant differences in social class distribution by year $(P<0 \cdot 0001)$, with 1986-1987 having lower proportions of social classes I and II compared with 2000-2001 and a higher proportion of social class IV. Significantly more people reported they were receiving benefits in 2000-2001 compared with 1986-1987 $(P<0 \cdot 0001)$ although a higher proportion reported they were in employment $(P<0 \cdot 0001)$. There were significant differences in marital status $(P<0 \cdot 0001)$, with a higher proportion being married in 1986-1987 compared with 2000-2001 and lower proportions being single and divorced/separated/widowed. There were substantial differences in household type between the two periods $(P<0.0001)$ with a higher proportion living alone and a higher proportion of single parents in 2000-2001 than in 1986-1987, as well as a lower proportion of households with dependant children and spouse.

Table 1 Demographic and socio-economic characteristics of the samples in 1986-1987 and 2000-2001

\begin{tabular}{|c|c|c|c|c|c|c|c|}
\hline \multirow[b]{2}{*}{ Variable } & \multicolumn{3}{|c|}{$1986-1987$ ( N 2197) } & \multicolumn{3}{|c|}{ 2000-2001 ( N 1724) } & \multirow[b]{2}{*}{$P$} \\
\hline & $n$ & Mean & SE & $n$ & Mean & SE & \\
\hline \multicolumn{8}{|l|}{ Age (years) } \\
\hline Men & 1087 & $38 \cdot 21$ & 0.417 & 1008 & $41 \cdot 90$ & 0.382 & 0.0001 \\
\hline Women & 1110 & $39 \cdot 27$ & 0.408 & 1243 & $41 \cdot 75$ & 0.346 & 0.0001 \\
\hline \multicolumn{8}{|l|}{ BMI $\left(\mathrm{kg} / \mathrm{m}^{2}\right)$} \\
\hline Men & 1074 & $24 \cdot 91$ & $0 \cdot 110$ & 810 & $27 \cdot 23$ & $0 \cdot 158$ & 0.0001 \\
\hline \multirow[t]{2}{*}{ Women } & 1101 & $24 \cdot 56$ & $0 \cdot 152$ & 978 & $26 \cdot 49$ & $0 \cdot 180$ & 0.0001 \\
\hline & & \multicolumn{2}{|c|}{$\%$} & \multicolumn{3}{|c|}{$\%$} & \\
\hline \multicolumn{8}{|l|}{ Region (\%) } \\
\hline Scotland & 191 & \multicolumn{2}{|c|}{$8 \cdot 7$} & 191 & \multicolumn{2}{|c|}{$8 \cdot 5$} & \\
\hline North & 564 & \multicolumn{2}{|c|}{$26 \cdot 4$} & 608 & \multicolumn{2}{|c|}{$27 \cdot 0$} & \\
\hline Central, South and Wales & 732 & \multirow{2}{*}{\multicolumn{2}{|c|}{$\begin{array}{l}33.8 \\
32.3\end{array}$}} & 485 & \multicolumn{2}{|c|}{$36 \cdot 9$} & \\
\hline London and the South East & 710 & & & 679 & & & 0.423 \\
\hline \multicolumn{8}{|l|}{ Social class (\%) } \\
\hline I: Professional & 67 & \multicolumn{2}{|c|}{$3 \cdot 2$} & 129 & \multicolumn{2}{|c|}{$5 \cdot 9$} & \\
\hline II: Managerial/Technical & 501 & \multicolumn{2}{|c|}{$23 \cdot 9$} & 674 & \multicolumn{2}{|c|}{$30 \cdot 7$} & \\
\hline Illa: Skilled (non-manual) & 567 & \multicolumn{2}{|c|}{$27 \cdot 1$} & 506 & \multicolumn{2}{|c|}{$23 \cdot 0$} & \\
\hline Illb: Skilled (manual) & 456 & \multirow{2}{*}{\multicolumn{2}{|c|}{$\begin{array}{l}21 \cdot 8 \\
18 \cdot 8\end{array}$}} & 386 & \multicolumn{2}{|c|}{$17 \cdot 6$} & \\
\hline IV: Semi-skilled & 392 & & & 365 & & & \\
\hline V: Unskilled & 106 & \multicolumn{2}{|c|}{$5 \cdot 1$} & 138 & & & 0.0001 \\
\hline Benefits (\%) & & & & & & & \\
\hline Yes & 272 & & & 428 & & & \\
\hline No & 1918 & & & 1823 & & & 0.0001 \\
\hline Employment status (\%) & & & & & & & \\
\hline Paid employment & 1545 & & & 1652 & & & \\
\hline Not in paid employment & 156 & & & 75 & & & \\
\hline Economically inactive & 484 & & & 524 & & & 0.0001 \\
\hline Marital status (\%) & & & & & & & \\
\hline Married & 1489 & & & 1143 & & & \\
\hline Single & 487 & & & 646 & & & \\
\hline Divorced/separated/widowed & 221 & & & 462 & & & 0.0001 \\
\hline Household type (\%) & & & & & & & \\
\hline Living alone & 155 & & & 464 & & & \\
\hline With spouse/partner, no dependant children & 742 & & & 768 & & & \\
\hline With other adults, no spouse/partner and no dependant children & 453 & & & 224 & & & \\
\hline With dependant children and spouse/partner & 771 & & & 604 & & & \\
\hline With dependant children, no spouse/partner & 76 & & & 191 & & & 0.0001 \\
\hline
\end{tabular}


Sociodemographic profile of 'compliers' and 'non-compliers' in 1986-1987 and 2000-2001

Table 2 presents demographic and socio-economic data for 'compliers' and 'non-compliers' in 1986-1987 and 2000-2001.

In 1986-1987 $12 \cdot 7 \%$ of participants were classified as 'compliers' (consuming 5 or more portions of fruit and vegetables per day). In 2000-2001 16.5\% were classified as 'compliers', a modest but statistically significant increase in the proportion consuming 5 or more portions of fruit and vegetables per day $\left(\chi^{2}=6.969, P=0 \cdot 0083\right)$.

Social class was significantly associated with daily consumption of 5 portions of fruit and vegetables in both 1986-1987 and 2000-2001, with larger proportions of 'compliers' in social classes I and II, and lower proportions in social classes IIIb, IV and V $(P<0 \cdot 0001)$. 'Noncompliers' were over-represented among those receiving benefits in both 1986-1987 and 2000-2001 $(P<0 \cdot 0001)$. There were differences between regions in 1986-1987, with more 'non-compliers' in Scotland and the North $(P=0 \cdot 006)$, but there were no significant differences in 2000-2001 $(P=0 \cdot 06)$.

Compared with single and divorced/separated/ widowed, there was a greater proportion of 'compliers' among married people in both 1986-1987 and 2000-2001 $(P<0 \cdot 0001)$. Regarding household type, in 1986-1987 those who were living alone and those living with a spouse and no dependant children were 'compliers' whereas those in households with dependant children and a spouse, those living with other adults and single-parent

Table 2 Demographic and socio-economic characteristics of 'compliers' and 'non-compliers' in 1986-1987 and 2000-2001

\begin{tabular}{|c|c|c|c|c|c|c|c|c|c|c|}
\hline \multirow[b]{3}{*}{ Variable } & \multicolumn{4}{|c|}{$1986-1987$} & \multirow[b]{3}{*}{$P$} & \multicolumn{5}{|c|}{$2000-2001$} \\
\hline & \multicolumn{2}{|c|}{$\begin{array}{l}\text { 'Compliers' } \\
\text { (N 323) }\end{array}$} & \multicolumn{2}{|c|}{$\begin{array}{l}\text { 'Non-compliers' } \\
\text { (N 1872) }\end{array}$} & & \multicolumn{2}{|c|}{$\begin{array}{l}\text { 'Compliers' } \\
\text { (N 353) }\end{array}$} & \multicolumn{2}{|c|}{$\begin{array}{l}\text { 'Non-compliers' } \\
(N \text { 1371) }\end{array}$} & \multirow[b]{2}{*}{$P$} \\
\hline & $n$ & $\%$ & $n$ & $\%$ & & $n$ & $\%$ & $n$ & $\%$ & \\
\hline \multicolumn{11}{|l|}{ Social class } \\
\hline I: Professional & 20 & $29 \cdot 9$ & 47 & $70 \cdot 1$ & & 46 & $46 \cdot 0$ & 54 & $54 \cdot 0$ & \\
\hline II: Managerial/Technical & 121 & $24 \cdot 2$ & 380 & $75 \cdot 9$ & & 147 & $27 \cdot 8$ & 381 & $72 \cdot 2$ & \\
\hline Illa: Skilled (non-manual) & 93 & $16 \cdot 4$ & 474 & $83 \cdot 6$ & & 75 & $18 \cdot 7$ & 326 & $81 \cdot 3$ & \\
\hline Illb: Skilled (manual) & 44 & $9 \cdot 7$ & 412 & $90 \cdot 4$ & & 41 & $14 \cdot 5$ & 241 & $85 \cdot 5$ & \\
\hline IV: Semi-skilled & 29 & $7 \cdot 4$ & 363 & $92 \cdot 6$ & & 34 & $12 \cdot 0$ & 249 & $88 \cdot 0$ & \\
\hline V: Unskilled & 9 & $8 \cdot 5$ & 97 & $91 \cdot 5$ & 0.0001 & 7 & 6.9 & 94 & $93 \cdot 1$ & 0.0001 \\
\hline \multicolumn{11}{|l|}{ Employment status } \\
\hline Paid employment & 240 & $15 \cdot 5$ & 1305 & $84 \cdot 5$ & & 282 & $22 \cdot 0$ & 998 & $78 \cdot 0$ & \\
\hline Not in paid employment & 10 & $6 \cdot 4$ & 146 & $93 \cdot 6$ & & 5 & $9 \cdot 4$ & 48 & $90 \cdot 6$ & \\
\hline Economically inactive & 74 & $15 \cdot 3$ & 410 & $84 \cdot 7$ & 0.009 & 66 & $16 \cdot 9$ & 325 & $83 \cdot 1$ & $0 \cdot 011$ \\
\hline \multicolumn{11}{|l|}{ Receiving benefits } \\
\hline Yes & 13 & $4 \cdot 8$ & 259 & $95 \cdot 2$ & & 27 & $8 \cdot 9$ & 278 & $91 \cdot 2$ & \\
\hline No & 310 & $16 \cdot 2$ & 1608 & $83 \cdot 8$ & 0.0001 & 326 & $23 \cdot 0$ & 1093 & $77 \cdot 0$ & 0.0001 \\
\hline \multicolumn{11}{|l|}{ Region } \\
\hline Scotland & 25 & $13 \cdot 1$ & 166 & $86 \cdot 9$ & & 26 & $21 \cdot 1$ & 97 & $78 \cdot 9$ & \\
\hline North & 61 & $10 \cdot 8$ & 503 & $89 \cdot 2$ & & 84 & $18 \cdot 6$ & 367 & $81 \cdot 4$ & \\
\hline Central, South and Wales & 114 & $15 \cdot 6$ & 618 & $84 \cdot 4$ & & 115 & $18 \cdot 4$ & 509 & $81 \cdot 6$ & \\
\hline London and the South East & 125 & $17 \cdot 6$ & 588 & $82 \cdot 4$ & 0.006 & 128 & $24 \cdot 3$ & 398 & $75 \cdot 7$ & 0.060 \\
\hline \multicolumn{11}{|l|}{ Marital status } \\
\hline Married & 242 & $16 \cdot 3$ & 1247 & $83 \cdot 8$ & & 221 & $24 \cdot 6$ & 679 & $75 \cdot 4$ & \\
\hline Single & 57 & $11 \cdot 7$ & 430 & $88 \cdot 3$ & & 69 & $14 \cdot 4$ & 410 & $85 \cdot 6$ & \\
\hline Divorced/separated/widowed & 26 & $11 \cdot 8$ & 195 & $88 \cdot 2$ & 0.020 & 63 & $18 \cdot 3$ & 282 & $81 \cdot 7$ & 0.0001 \\
\hline \multicolumn{11}{|l|}{ Household type } \\
\hline Living alone & 29 & $18 \cdot 7$ & 126 & $81 \cdot 3$ & & 74 & $21 \cdot 5$ & 270 & $78 \cdot 5$ & \\
\hline With spouse/partner, no dependant children & 149 & $20 \cdot 1$ & 593 & $79 \cdot 9$ & & 167 & $27 \cdot 7$ & 435 & $72 \cdot 3$ & \\
\hline $\begin{array}{l}\text { With other adults, no spouse/partner and no } \\
\text { dependant children }\end{array}$ & 52 & $11 \cdot 5$ & 401 & $88 \cdot 5$ & & 23 & $14 \cdot 0$ & 141 & $86 \cdot 0$ & \\
\hline With dependant children and spouse/partner & 92 & 11.9 & 679 & $88 \cdot 1$ & & 82 & $17 \cdot 3$ & 392 & $82 \cdot 7$ & \\
\hline With dependant children, no spouse/partner & 3 & $4 \cdot 0$ & 73 & $96 \cdot 1$ & 0.0001 & 7 & $5 \cdot 0$ & 133 & $95 \cdot 0$ & 0.0001 \\
\hline \multicolumn{11}{|l|}{ Gender } \\
\hline Male & 93 & $10 \cdot 5$ & 790 & $89 \cdot 5$ & & 96 & $16 \cdot 8$ & 477 & $83 \cdot 3$ & \\
\hline Female & 130 & $14 \cdot 8$ & 746 & $85 \cdot 2$ & 0.007 & 121 & $16 \cdot 3$ & 620 & $83 \cdot 7$ & 0.837 \\
\hline \multicolumn{11}{|l|}{ Age (years) } \\
\hline $19-24$ & 38 & $9 \cdot 4$ & 365 & $90 \cdot 6$ & & 10 & $7 \cdot 2$ & 129 & $92 \cdot 8$ & \\
\hline $25-34$ & 73 & $14 \cdot 4$ & 434 & $85 \cdot 6$ & & 38 & $10 \cdot 2$ & 333 & $89 \cdot 8$ & \\
\hline $35-49$ & 107 & $14 \cdot 6$ & 624 & $85 \cdot 4$ & & 147 & $21 \cdot 6$ & 535 & $78 \cdot 5$ & \\
\hline 50-64 & 107 & $19 \cdot 2$ & 449 & $80 \cdot 8$ & 0.0001 & 148 & $29 \cdot 7$ & 374 & $70 \cdot 3$ & 0.0001 \\
\hline \multicolumn{11}{|l|}{ BMI $\left(\mathrm{kg} / \mathrm{m}^{2}\right)$} \\
\hline Underweight $(<18 \cdot 5)$ & 8 & $17 \cdot 4$ & 38 & $82 \cdot 6$ & & 9 & $36 \cdot 0$ & 16 & $64 \cdot 0$ & \\
\hline Normal weight $(18 \cdot 5-24 \cdot 9)$ & 127 & $12 \cdot 9$ & 854 & $87 \cdot 1$ & & 77 & $17 \cdot 0$ & 376 & $83 \cdot 0$ & \\
\hline Overweight $(25 \cdot 0-29 \cdot 9)$ & 57 & $10 \cdot 6$ & 482 & $89 \cdot 4$ & & 73 & $16 \cdot 2$ & 379 & $83 \cdot 8$ & \\
\hline Obese $(\geq 30 \cdot 0)$ & 28 & $16 \cdot 0$ & 146 & $84 \cdot 0$ & $0 \cdot 274$ & 46 & $15 \cdot \overline{5}$ & 251 & $84 \cdot 5$ & 0.068 \\
\hline
\end{tabular}


households were more likely to be in the 'non-compliers' group $(P<0 \cdot 0001)$. The results were similar in 2000-2001 $(P<0 \cdot 0001)$.

There was significant gender difference in 1986-1987 with $10 \cdot 5 \%$ of men being 'compliers' compared with $14 \cdot 8 \%$ of women $(P=0 \cdot 007)$, whereas there was no significant difference in 2000-2001, with both genders having $16-17 \%$ of 'compliers' $(P=0 \cdot 837)$. 'Compliers' were more likely to be in the older age groups, compared with the younger age groups, in both 1986-1987 and 2000-2001 ( $P<0 \cdot 0001)$.

\section{Logistic regression model}

Table 3 presents the logistic regression model for those who complied, according to demographic and socioeconomic variables, controlled for cluster sampling.

Those aged 35-49 years $(P=0 \cdot 01)$ and 50-64 years $(P<0 \cdot 001)$ were significantly more likely to be 'compliers', compared with younger ages. There was a significant association by region, with Central, South and Wales and London and the South East having higher proportions of 'compliers' compared with Scotland and the North ( $P=0 \cdot 001$ and $P=0 \cdot 002$, respectively). Regarding social class, the odds ratios indicated that a participant was less likely to be a 'complier' if in social class IIIb $(P=0.035)$ and below $(P=0.001$ and $P=0.007$ for social class IV and $\mathrm{V}$, respectively).

The odds of being a 'complier' was less in those with no paid work or inactive compared with being in paid employment $(P=0.029$ and $P=0.005$, respectively). There was no significant relationship between marital status or household type and being a 'complier', nor was there a relationship with receipt of benefits. The likelihood of being a 'complier' was greater for females $(P=0 \cdot 015)$.

There was a significant period effect with an increase in 'compliers' from 1986-1987 to 2000-2001 $(P=0 \cdot 004)$ and a significant interaction between the year and the

Table 3 Logistic regression model for compliance with 5 or more portions of fruit and vegetables per day according to demographic and socio-economic variables

\begin{tabular}{|c|c|c|c|}
\hline Variable & OR & $95 \% \mathrm{Cl}$ & $P$ \\
\hline \multicolumn{4}{|l|}{ Age (years) } \\
\hline $19-24$ & $1 \cdot 00$ & Ref. & \\
\hline $25-34$ & $1 \cdot 47$ & $0.939,2 \cdot 307$ & 0.090 \\
\hline $35-49$ & $2 \cdot 22$ & $1 \cdot 412,3 \cdot 508$ & $0 \cdot 010$ \\
\hline $50-64$ & $4 \cdot 08$ & $2 \cdot 400,6 \cdot 935$ & 0.0001 \\
\hline \multicolumn{4}{|l|}{ Region } \\
\hline Scotland & 1.00 & Ref. & \\
\hline North & $1 \cdot 56$ & $0.960,2 \cdot 552$ & 0.072 \\
\hline Central, South and Wales & $2 \cdot 25$ & $1 \cdot 532,3 \cdot 310$ & 0.001 \\
\hline London and the South East & $2 \cdot 00$ & $1 \cdot 320,3 \cdot 047$ & 0.002 \\
\hline \multicolumn{4}{|l|}{ Social class } \\
\hline I: Professional \& II: Managerial/Technical & $1 \cdot 00$ & Ref. & \\
\hline Illa: Skilled (non-manual) & $1 \cdot 18$ & $0.775,1 \cdot 803$ & 0.487 \\
\hline Illb: Skilled (manual) & $0 \cdot 64$ & $0.420,0.967$ & 0.035 \\
\hline IV: Semi-skilled & 0.47 & $0.303,0.732$ & 0.001 \\
\hline V: Unskilled & 0.49 & $0.294,0.816$ & 0.007 \\
\hline \multicolumn{4}{|l|}{ Benefits } \\
\hline Yes & $1 \cdot 00$ & Ref. & \\
\hline No & $1 \cdot 31$ & $0.948,1.826$ & 0.098 \\
\hline \multicolumn{4}{|l|}{ Employment status } \\
\hline Paid employment & $1 \cdot 00$ & Ref. & \\
\hline Not in paid employment & 0.60 & $0.392,0.930$ & 0.029 \\
\hline Economically inactive & 0.63 & $0.463,0.860$ & 0.005 \\
\hline \multicolumn{4}{|l|}{ Marital status } \\
\hline Married & $1 \cdot 00$ & Ref. & \\
\hline Single & $0 \cdot 82$ & $0.481,1.399$ & 0.459 \\
\hline Divorced/separated/widowed & 0.68 & $0 \cdot 383,1 \cdot 210$ & $0 \cdot 184$ \\
\hline \multicolumn{4}{|l|}{ Household type } \\
\hline Living alone & $1 \cdot 00$ & Ref. & \\
\hline With spouse/partner, no dependant children & $1 \cdot 66$ & $0.910,3.033$ & 0.096 \\
\hline With other adults, no spouse/partner and no dependant children & 1.44 & $0.909,2.289$ & $0 \cdot 117$ \\
\hline With dependant children and spouse/partner & $1 \cdot 31$ & $0 \cdot 700,2 \cdot 467$ & 0.386 \\
\hline With dependant children, no spouse/partner & $0 \cdot 86$ & $0.453,1.638$ & 0.641 \\
\hline \multicolumn{4}{|l|}{ Gender } \\
\hline Male & $1 \cdot 00$ & Ref. & \\
\hline Female & 1.51 & $1 \cdot 089,2 \cdot 118$ & 0.015 \\
\hline \multicolumn{4}{|l|}{ Survey year } \\
\hline $1986-1987$ & $1 \cdot 00$ & Ref. & \\
\hline 2000-2001 & 1.67 & $1 \cdot 354,2 \cdot 358$ & 0.004 \\
\hline Interaction: year $\times$ gender & $1 \cdot 84$ & $1 \cdot 056,3 \cdot 228$ & 0.032 \\
\hline
\end{tabular}

Ref., referent category. 
relationship with gender $(P=0 \cdot 032)$. In 1986-1987, the odds of being a 'complier' was 1.58 for women compared with men $(P=0 \cdot 013)$ and in 2000-2001 the odds was $0.84(P=0 \cdot 475)$. The odds of a man being a 'complier' in the second compared with the first survey was $2 \cdot 25$ $(P=0 \cdot 001)$ and for women the odds was $1 \cdot 21(P=0 \cdot 259$; stratified subgroup analyses available on request).

\section{Discussion}

In the present study, based on comparison of data from the Dietary and Nutritional Surveys of British Adults, there was an increase in the proportion of adults who consumed 5 or more portions of fruit and vegetables per day from $12 \cdot 7 \%$ in $1986-1987$ to $16 \cdot 5 \%$ in $2000-2001$. Improvements were seen across social class groups. Differences between men and women and between regions reduced between 1986-1987 and 2000-2001. Those on benefits, those unemployed or economically inactive and couples or lone parents with dependant children were less likely to comply than their comparators in 1986-1987 and 2000-2001.

The survey data are of high quality, being based on nationally representative samples, weighed dietary records and validated methods. Our observations were based in the first instance on comparison of findings in two crosssectional surveys and subsequently strengthened by formal testing in logistic regression analysis including survey year as a variable. The sample from 2000-2001 contained a greater proportion of older people and people in upper social classes than did the 1986-1987 sample. In both surveys response rates were calculated for the number of respondents completing full $7 \mathrm{~d}$ weighed dietary records as a proportion of the number of eligible respondents. As the response rate fell from $70 \%$ to $47 \%$, bias introduced by self-selection of participants pursuing a healthier lifestyle is possible. Extensive analysis of response rates by sociodemographic group, region and recruitment waves showed consistent changes in response rates across the entire population ${ }^{(16,17)}$; and we note that the changes in age distribution and social class are consistent with demographic trends and that independent effects for age, region, employment status, marital status and survey year are confirmed in logistic regression analyses. In both years surveys were conducted in four rounds across spring, summer, autumn and winter. It was not possible to formally adjust for seasonality as date of the survey was only made available for the later data set. However, given the systematic sampling approach which included consideration of geographic units and similar response rates across rounds in each survey, we are not anticipating that a residual seasonality effect will have caused an important bias in our results.

A study comparable to ours is that of Roos et al. ${ }^{(21)}$ looking at socio-economic differences in daily vegetable intake from 1979 to 2002 among Finish adults. In that study, daily consumption of vegetables was more common among those with higher income or higher education level, and among women, during the whole study period. However, the increase was higher in the lower educational and lower income groups during the study period, meaning that the socio-economic divide narrowed for vegetable intake during this period. In contrast, analyses of the Dutch National Food Consumption Surveys for 1987-1988, 1992 and 1997-1998 demonstrated a decrease in consumption of fruit and vegetables over the period $^{(22)}$. Socio-economic differentials were present at baseline, which were more marked in women than in men, and changes towards lower consumption of fruit and vegetables were seen in all socio-economic groups in later years.

Meanwhile, in the USA the proportion complying with fruit and vegetable goals appears to have remained static through the same time period. Casagrande et $a l .{ }^{(23)}$ examined data from the National Health and Nutrition Examination Survey and found that $24 \cdot 3 \%$ complied with the recommended 5 or more portions of fruit and vegetables per day in 1988-1994 and 23.6\% in 1999-2002. Blanck et $a l^{(24)}$ used a different data source (the Behavioral Risk Factor Surveillance System) to show for both men and women that the percentage who met 5 or more per day did not change: $20 \cdot 6 \%$ in 1994 and 20.3\% in 2005. Complementary analyses of the same data indicated that there were actually increases in fruit and vegetable consumption in 1990-1996(25), but these fell away in $1994-2000^{(26)}$.

The years between the Dietary and Nutritional Surveys of 1986-1987 and 2000-2001 were at the beginning of a phase of food policy direction reinforced by statements of explicit recommendations $^{(7,8)}$ and characterised by early selective and universalist approaches towards improving fruit and vegetable consumption in the UK. The former were driven by and large by the voluntary sector and public sector groups, and ranged in character from supplying food to teaching cooking and budgeting skills. At the same time various retailers were beginning to accept a notion of social responsibility and introduce economy ranges of food and business models that did not depend exclusively on out-of-town supermarkets ${ }^{(8)}$. In England, there was little by way of centrally coordinated food policy, with the Department of Health and the Ministry of Agriculture, Fisheries and Food adopting principally a monitoring role ${ }^{(27)}$. Lack of leadership could be less true for the devolved administration in Scotland and it is interesting to speculate whether the changes in regional differentials between the two surveys reflect the effective implementation of elements of the Scottish Diet Action Plan ${ }^{(7)}$.

Some encouragement should be taken from the findings of our research in that there has been an increase in the proportion of 'compliers' between 1986-1987 and 
2000-2001 and closure of the gender gap. The data also indicate the continuing challenge of social class, where a fourfold difference in the proportion of 'compliers' persists between social class I and social class V. The evidence base for interventions directed towards individuals and groups has grown considerably in the last decade and policy can be framed around selective and universalist interventions that are evidence based ${ }^{(28)}$ and/or can build on work that has gone before in communicating messages to the public and to specific segments of the population in particular circumstances $^{(29,30)}$.

We hope that momentum has not been lost since 2001 and note that Dowler ${ }^{(31)}$ has recently presented a framework for addressing households' nutritional needs, summarising the range of policy responses in the UK to inequalities in diet and nutrition broadly under the remit of 'health', 'education' and 'commercial food access'. Data from the Dietary and Nutritional Survey for 2008-2009 are now available and early indications are that there has been a further improvement in compliance with fruit and vegetable goals $^{(32)}$. We hope it may be possible eventually to see an extended analysis similar to the work presented here, using systematic methods to examine trends across all three surveys.

\section{Acknowledgements}

This research received no specific grant from any funding agency in the public, commercial or not-for-profit sectors. This paper has not been published elsewhere in part or in full or been submitted elsewhere. There are no financial or other relationships that lead to competing interests. Both authors have read and approved the revised paper for publication, both have been involved in the conception, writing and revising of the paper. J.A.P. did the analysis and S.R. wrote the paper.

\section{References}

1. Lock K, Pomerleau J, Causer L et al. (2005) The global burden of disease attributable to low consumption of fruit and vegetables: implication for the global strategy on diet. Bull World Health Organ 83, 100-108.

2. National Institute of Public Health (1997) Determinants of the Burden of Disease in the EU. Stockholm: National Institute of Public Health.

3. Mathers C, Vos T \& Stevenson C (1999) The Burden of Disease and Injury in Australia. Canberra: Australian Institute of Health and Welfare.

4. Tobias M, Jackson G, Yeh LC et al. (2007) Do healthy and unhealthy behaviours cluster in New Zealand? Aust N ZJ Public Health 31, 155-163.

5. The Scottish Office Home and Health Department (1993) The Scottish Diet. Report of a Working Party to the Chief Medical Officer for Scotland. London: HMSO.

6. Department of Health (1994) Nutritional Aspects of Cardiovascular Disease. Report of the Cardiovascular Review Group, Committee on Medical Aspects of Food Policy. Report on Health and Social Subjects no. 46. London: HMSO.
7. The Scottish Office (1994) The Scottish Diet. Report of the Scottish Health Services Advisory Council Working Group chaired by Philip James. Edinburgh: The Scottish Office.

8. Department of Health (1996) Low Income, Food, Nutrition and Health: Strategies for Improvement. A Report for the Low Income Project Team to the Nutritional Task Force. London: Department of Health.

9. World Health Organization (2001) The First Action Plan for Food and Nutrition Policy, WHO European Region, 2000-2005. Copenhagen: WHO Regional Office for Europe.

10. Billson H, Pryer JA \& Nichols R (1999) Variation in fruit and vegetable consumption among adults in Britain. An analysis from the dietary and nutritional survey of British adults. Eur J Clin Nutr 53, 946-952.

11. Hunt CJ, Nichols RN \& Pryer JA (2000) Who complied with fruit and vegetable population goals? Eur J Clin Nutr 10, 178-184.

12. Williams C (1995) Healthy eating: clarifying advice about fruit and vegetables. BMJ 310, 1453-1455.

13. Williams C (1997) Recommendations and current consumption patterns: how big is the gap? In At Least Five a Day. Strategies to Increase Vegetable and Fruit Consumption, pp. 19-34 [I Sharpe, editor]. London: National Heart Forum.

14. World Health Organization (2003) Diet, Nutrition and the Prevention of Chronic Diseases. Report of a Joint WHO/ FAO Expert Consultation. WHO Technical Report Series no. 916. Geneva: WHO.

15. World Cancer Research Fund/American Institute of Cancer Research (2007) Food, Nutrition, Physical Activity, and the Prevention of Cancer: A Global Perspective. Washington, DC: AICR.

16. Gregory J, Foster K, Tyler H et al. (1990) The Dietary and Nutritional Survey of British Adults. London: HMSO.

17. Hoare J, Bates CJ, Prentice A et al. (2004) The National Diet and Nutrition Survey: Adults Aged 19-64 Years. Summary Report. London: HMSO.

18. Kish L (1949) A procedure for objective respondent selection within the household. J Am Stat Assoc $\mathbf{4 4}$, 380-387.

19. Office for Population Census and Surveys (1980) Classification of Occupations. London: HMSO.

20. StataCorp LP (2007) Stata Survey Data Reference Manual, Release 10. College Station, TX: Stata Press.

21. Roos E, Talala K, Laaksonen M et al. (2008) Trends of socioeconomic differences in daily vegetable consumption, 1979-2002. Eur J Clin Nutr 62, 823-833.

22. Hulshof KFAM, Brussard JH, Kruizinga AG et al. (2003) Socio-economic status, dietary intake and 10 y trends: the Dutch National Food Consumption Survey. Eur J Clin Nutr 57, 128-137.

23. Casagrande SS, Wang Y, Anderson C et al. (2007) Have Americans increased their fruit and vegetable intake? Trends between 1988 and 2002. Am Prev Med 32, 257-263.

24. Blanck HM, Gillespie C, Kimmons JE et al. (2008) Trends in fruit and vegetable consumption among US men and women, 1994-2005. Prev Chronic Dis 5, A35.

25. Ruowei L, Serdula M, Balnd S et al. (2000) Trends in fruit and vegetable consumption among adults in 16 US states: Behavioral Risk Factor Surveillance System, 1990-1996. Am J Public Health 90, 777-781.

26. Serdula MK, Gillespie C, Kettel-Kahan L et al. (2004) Trends in fruit and vegetable consumption among adults in the United States: Behavioral Risk Factor Surveillance System, 1994-2000. Am J Public Health 94, 1014-1018.

27. Nelson M (1997) Developments in the UK: work of the Low Income Project team. Proc Nutr Soc 56, 91-100.

28. Pommerleau J, Lock K, Knai C et al. (2005) Interventions to increase adult fruit and vegetable intake can be 
effective: a systematic review of the literature. J Nutr $\mathbf{1 3 5}$, 2486-2495.

29. Pollard CM, Miller MR, Daly AM et al. (2007) Increasing fruit and vegetable consumption: success of the Western Australian Go for $2 \& 5$ campaign. Public Health Nutr 11, 314-320.

30. Bremner P, Dalziel D \& Evans L (2006) Evaluation of the 5 a Day Programme. London: Evaluation and Research Team, Big Lottery Fund.
31. Dowler E (2008) Policy initiatives to address low income households' nutritional needs in the UK. Proc Nutr Soc 67, 289-300.

32. Food Standards Agency (2010) National Diet and Nutrition Survey: headline results from year 1 (2008/2009). http:// collections.europarchive.org/tna/20100907111047/http://food. gov.uk/science/dietarysurveys/ndnsdocuments/ndns0809year1 (accessed January 2011). 